\title{
Identification of MACC1 as a novel prognostic marker in hepatocellular carcinoma
}

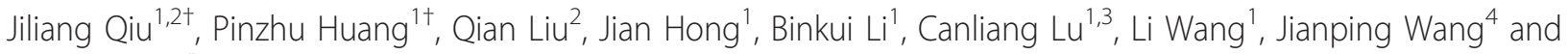 \\ Yunfei Yuan ${ }^{1 *}$
}

\begin{abstract}
Background: Metastasis-associated in colon cancer-1 (MACC1) is a newly identified gene that plays a role in colon cancer metastasis through upregulation of c-MET proto-oncogene (c-MET). However, the value of MACC1 as a potential biomarker for hepatocellular carcinoma (HCC) remains unknown.

Methods: MACC1 mRNA expression in 128 HCC tissues was examined by quantitative polymerase chain reaction. To show the potential correlation of MACC1 and c-MET, c-MET was also analysed.

Results: MACC1 was more highly expressed in HCC than in non-HCC tissues $(P=0.009)$. High MACC1 expression was significantly increased in cases with high alpha fetoprotein (AFP) $(P=0.025)$. A positive correlation was found between MACC1 and c-MET mRNAs $(r=0.235, P=0.009)$. Both univariate and multivariate analyses revealed that MACC1 expression was associated with overall survival (OS) and disease-free survival (DFS). Moreover, stratified analysis showed that tumour-node-metastasis (TNM) stage I patients with high MACC1 levels had shorter OS and DFS than those with low MACC1.
\end{abstract}

Conclusions: MACC1 may identify low- and high-risk individuals with HCC and be a valuable indicator for stratifying the prognosis of TNM stage I patients. MACC1 may serve as a novel biomarker for HCC.

Keywords: MACC1, c-MET, hepatocellular carcinoma, prognosis

\section{Background}

Hepatocellular carcinoma (HCC) is one of the most common solid tumours and prevalent fatal cancers worldwide, especially in East Asia and Sub-Saharan Africa [1,2]. Recently, HCC mortality rate has increased faster than the mortality rates for any other leading cancers in the United States [3,4]. Surgical resection or liver transplantation offers the chance of a cure, but only 30 $40 \%$ of HCC patients are eligible for curative treatments, even in developed countries [5]. The HCC recurrence rate is as high as $54 \%$ at 5 years, even in early-stage HCC after radical resection [6,7]. Survival may vary widely among HCC patients with the same clinicopathologic features, which is most likely attributable to the heterogeneity of the biological behaviour of tumour cells

\footnotetext{
* Correspondence: yuanyf@mail.sysu.edu.cn

+ Contributed equally

'State Key Laboratory of Oncology in South China/Department of Hepatobiliary Oncology, Sun Yat-sen University Cancer Center, Guangzhou, China

Full list of author information is available at the end of the article
}

$[8,9]$. Although recent studies have unravelled some aberrantly expressed genes contributing to different prognoses in HCC, the molecular markers that help to predict early recurrence and serve as potential targets remain limited.

The importance of understanding the molecular biology of HCC has recently gained considerable attention, as molecular targeting therapy has shown encouraging results for many malignancies $[10,11]$. The key signal transduction pathways implicated in the pathogenesis of liver cancer include the PI3K/Akt/mTOR pathway [12], Wnt/ $/$-catenin signalling cascade [13], and HGF/c-MET pathway [14]. Recently, numerous disorders related to deregulation of the HGF/c-MET axis have been reported $[15,16]$. Aberrant activity of c-MET elicits multiple cellular responses regulating cell morphogenesis, migration, and breakdown of the extracellular matrix. Dysregulation of c-MET is common in HCC [17], although the exact mechanisms of this pathway in the carcinogenesis of $\mathrm{HCC}$ are still under investigation. As compounds that 
target the HGF/c-MET pathway are developed, new treatments for c-MET-triggered malignancies may be designed and the sensitivity of molecular-targeted drugs that are in clinical use may be improved $[18,19]$.

Poor prognosis of $\mathrm{HCC}$ is often associated with a high potential of vascular invasion and metastasis [20,21]. cMET is one of the key players in the processes of dissociation, angiogenesis, and migration of tumour cells in HCC [17]. Metastasis-associated in colon cancer-1 (MACC1), a new gene associated with colon cancer in primary and metastatic carcinomas, promotes tumour cell growth as well as the development of distant metastases [22]. Overexpression of MACC1 induces downstream activation of $\mathrm{HGF} / \mathrm{c}-\mathrm{MET}$ and facilitates metastasis of colon cancer, while silencing of MACC1 leads to reduced tumour proliferation, decreased cell migration, and a lack of new metastases, indicating the importance of MACC1 in the phases of cancer progression. Although MACC1 has been studied in colon carcinoma, little is known about its role in HCC. To address this issue, we evaluated the expression of MACC1 mRNA to determine whether $M A C C 1$ expression is of prognostic significance in HCC. Given the tight correlation between MACC1 and c-MET in colon cancer, we also examined the expression level of c-MET mRNA to determine whether such correlation exists in HCC.

\section{Methods}

\section{Cell lines}

Four human HCC cell lines, specifically HepG2, SMMC7721, MHCC-97H, and MHCC-97L, and one immortalised nontumourigenic normal human hepatocyte cell line, L-02, were used to screen the expression of MACC1. The hepatoma cell line HepG2 was purchased from the American Type Culture Collection (Manassas, VA). L-02, SMMC-7721, MHCC-97H and MHCC-97L were obtained from the Type Culture Collection of the Chinese Academy of Sciences (Shanghai, China) and maintained under recommended culture conditions. Cells were grown at $37^{\circ} \mathrm{C}$ in a humidified incubator containing $5 \% \mathrm{CO}_{2}$. RNA was extracted from exponentially growing cells.

\section{Study population and sample collection}

A total of 128 pairs of HCC tissues and adjacent nontumorous liver tissues were obtained from patients who underwent hepatectomy consecutively in a single group at the Department of Hepatobiliary Surgery, Sun Yatsen Cancer Center, between January 2001 and December 2006 and who fulfilled the following criteria: (1) exclusive treatment with chemotherapy or radiotherapy before tumour excision, (2) no evidence of concomitant extrahepatic disease, (3) no simultaneous use of local treatment modalities (i.e., radiofrequency ablation, microwave ablation). The patients included 116 males (90.6\%) and 12 females (9.4\%), with a median age of 50 years (range 23-79 years). Tumour size ranged from 1.2 to $19.0 \mathrm{~cm}$, with a median of $6.0 \mathrm{~cm}$. All tumours were histologically diagnosed as HCC with Edmondson-Steiner grade I in 8 cases, grade II in 61 , grade III in 54 , and grade IV in 5 . The tumour stages were classified according to the 6th Edition tumour-node-metastasis (TNM) classification of the International Union Against Cancer [23]. Sixty-seven cases were classified as stage I, 26 as stage II, and 35 as stage III. In this study, nontumorous tissues adjacent to tumour (NT) were defined as $2.0 \mathrm{~cm}$ from the margin, which were confirmed negative by histological examination, as used in other studies $[24,25]$. Twenty normal non-cirrhotic liver tissue samples $(\mathrm{N})$, which were from patients with liver haemangioma or focal nodular hyperplasia, were included as controls. All specimens were obtained immediately after surgical resection, snap-frozen in liquid nitrogen, and kept at $-80^{\circ} \mathrm{C}$ until use. All recruited patients provided written informed consent before hepatectomy, and the study protocol was approved by the Ethics Committee of Sun Yat-sen University Cancer Center.

\section{Reverse-transcription PCR analysis}

All samples were evaluated in a blinded reverse-transcription polymerase chain reaction (RT-PCR) procedure without knowledge of the clinicopathological or follow-up data until the PCR results were finalised. PCR was performed as described previously [26]. Briefly, total RNA was isolated with TRIzol- $\mathrm{A}^{+}$agent and treated with DNase I (Invitrogen Inc., Carlsbad, CA) to remove DNA contamination. Reverse transcription was performed with the SuperScript RT kit (Promega Inc., Madison, WI) following the manufacturer's instructions. The cDNA templates were subjected to PCR amplification. The reaction conditions for $M A C C 1$ were as follows: pre-denaturation at $94^{\circ}$ for $5 \mathrm{~min}$; 34 cycles of denaturation at $94^{\circ}$ for $30 \mathrm{~s}$, annealing at $60^{\circ}$ for $30 \mathrm{~s}$ and extension at $72^{\circ}$ for $30 \mathrm{~s}$; and final extension at $72^{\circ}$ for $10 \mathrm{~min}$. The final products were analysed by $2.0 \%$ agarose gel electrophoresis and stained with ethidium bromide. To detect any potential genomic DNA contamination, PCR reactions were also performed in RNA control samples that lacked reverse transcriptase during cDNA synthesis. Each PCR was performed in duplicate.

\section{Real-time quantitative PCR analysis}

Real-time quantitative PCR (Q-PCR) was performed in the same batch of CDNA prepared for RT-PCR to quantify MACC1 mRNA. Moreover, to explore the correlation of MACC1 and c-MET, c-MET mRNA was also quantified in 128 paired tumour specimens. The primer sets were 5'-TTCTTTTGATTCCTCCGGTGA-3' 
(forward) and 5'-ACTCTGATGGGCATGTGCTG-3' (reverse) for MACC1; 5'-GGATGCGTGCATTTATCAGA-3' (forward) and 5'-GTTGATAGGGCAGACGTTCG-3' (reverse) for 18s rRNA; and 5'GCTAAAATGCTGGCACCCTAA-3' (forward) and 5'ATAGTGCTCCCCAATGAAAGTAGAGA-3' (reverse) for c-Met. Q-PCR was performed with an ABI Prism 7900 HT Sequence Detection System (Applied Biosystems) and SYBR green I Master Mix kit (Invitrogen). 18s rRNA was analysed to normalise Q-PCR data. The threshold cycle $(\mathrm{Ct})$ value for triplicate reactions was averaged, and the relative genomic expression was calculated by $2^{-\Delta \Delta \mathrm{Ct}}$ value $[\triangle \mathrm{Ct}=\mathrm{Ct}(M A C C 1)-\mathrm{Ct}(18 \mathrm{~s})]$ [27]. Melting curves were performed to ensure only a single product was amplified.

\section{Follow-up}

The follow-up duration was defined as the interval between the date of operation and the date of death or last follow-up. The study was censored on 31 January 2010. The median follow-up time was 30.5 months, ranging from 3 to 85 months. All patients were followed up every 1-3 months in the first year and every 3-6 months thereafter. The follow-up protocol included physical examination, serum alpha-fetoprotein (AFP) level, chest $\mathrm{X}$-ray, and abdominal ultrasonography. Computed tomography and/or magnetic resonance imaging and/or positron emission tomography were performed when intrahepatic relapse or distant metastasis was suspected. During the course of follow-up, 64 of 128 patients (50.0\%) were found with intrahepatic recurrence, 18 patients (14.1\%) developed distant metastases, 49 patients $(38.3 \%)$ died of cancer-related causes, and 79 patients $(61.7 \%)$ were still alive.

\section{Statistical analysis}

All statistical analyses were carried out using the SPSS 16.0 statistical software package (SPSS Inc., Chicago, IL). The chi-square test or Fisher's exact test was used to comparison of frequencies. Spearman's correlation test was applied to analyse the correlation. Overall and disease-free survival curves were generated using the Kaplan-Meier method, and the difference between curves was assessed by the log-rank test. Independent prognostic factors were estimated by the Cox proportional hazards stepwise regression model. All $P$ values were 2 -sided. A $P$ value of less than 0.05 was considered statistically significant.

\section{Results}

MACC1 expression in human hepatoma cell lines and HCC tissues

We first examined $M A C C 1$ expression in five liver cell lines. RT-PCR showed that there was a lack of $M A C C 1$ expression in the normal liver cell line L-02, while all of four hepatoma cell lines (SMMC-7721, Hep-G2, MHCC-97L and MHCC-97H) expressed MACC1 mRNA (Figure 1A). Of 128 paired HCC patients' specimens, the frequency of $M A C C 1$-positive expression was significantly higher in HCC tissues $(53 / 128,41.4 \%)$ than in the corresponding non-tumorous liver tissues (27/ $128,21.1 \%, P<0.001)$. The expression of $M A C C 1$ mRNA in normal non-cirrhotic liver tissues was undetectable (Figure 1B).

Similar results were obtained from the same batch of cell lines using Q-PCR, which indicated high MACC1 mRNA expression in liver cancer cell lines, while there was low expression in normal liver cells (Figure 1C). In 128 paired HCC patients' specimens, Q-PCR showed that MACC1 mRNA expression was higher in HCC tissues than in adjacent non-tumorous liver tissues or normal tissues $(P=0.009, P=0.008$, respectively) (Figure 1D). The dissociation curve showed a single peak as expected for MACC1 (data not shown). As we expected, Spearman's correlation test showed that the high-level expression of MACC1 detected by Q-PCR always indicated positive expression MACC1 according to RT-PCR $(r=0.223, P=0.011)$.

\section{Correlation between MACC1 and c-MET mRNA expression}

To address whether MACC1 and c-MET mRNA levels were correlated, Q-PCR was applied to compare them in 128 paired $\mathrm{HCC}$ specimens. When the expression levels of both MACC1 and c-MET were plotted on a scatterplot diagram, the positive relationship became clear (Figure 2A). There was indeed a significant positive correlation between the expression levels of MACC1 and c-MET ( $r=0.235, P=0.009$, Spearman's correlation test). In addition, the expression level of c-MET was significantly higher in HCC tissues compared with adjacent non-cancerous tissues $(P<0.001)$ (Figure $2 \mathrm{~B})$.

\section{Correlation of MACC1 mRNA expression and clinicopathologic parameters}

Next, to explore potential cutoff values for $M A C C 1$, a threshold value was chosen using a minimum $P$ value approach as described by Mazumdar et al. [28]. In the multivariable setting, the level of MACC1 in HCC tissue that was associated with survival in terms of the minimum $P$ value was 2.3 -fold that of the non-cancerous tissue level. In the present study, 51 patients with 2.3-fold or more increased MACC1 in HCC tissues were defined as high-level, and 77 cases with below 2.3-fold expression were consider low-level. It should be mentioned that among 128 patients, 5 patients labelled as positive with conventional PCR were classified into the low group, while 3 MACC1-negative patients belonged to the high group. The slight inconsistency between Q- 

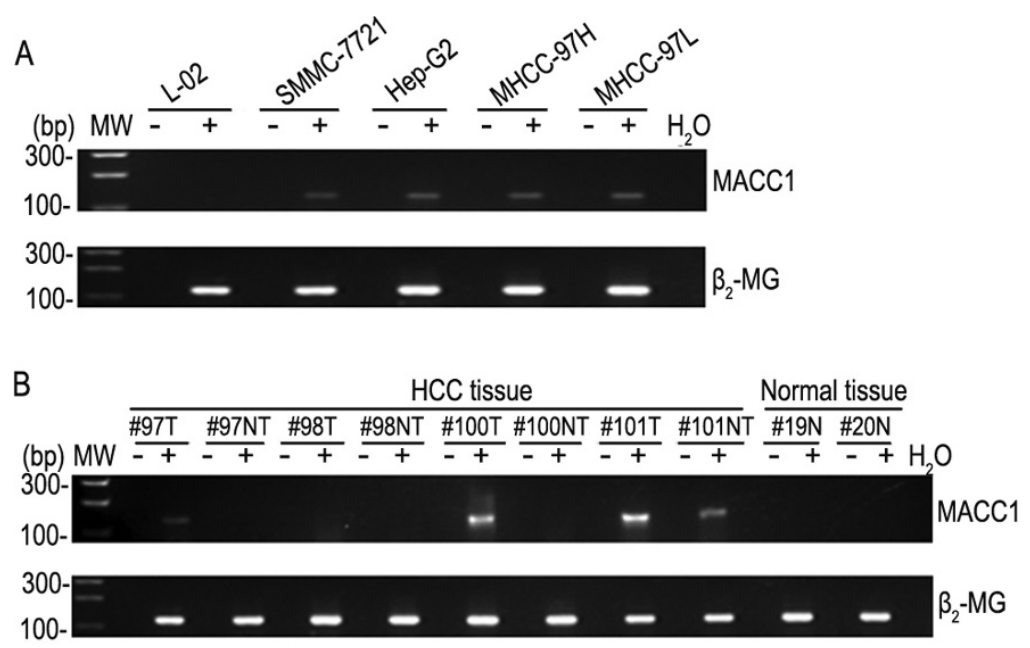

C

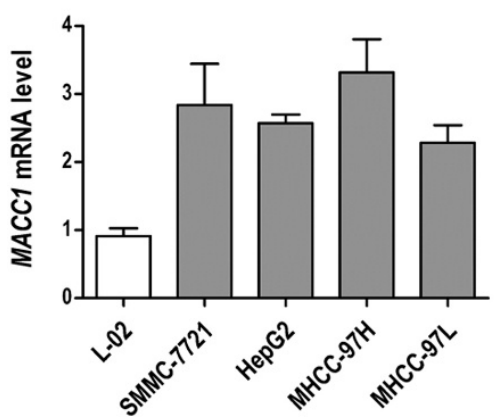

D

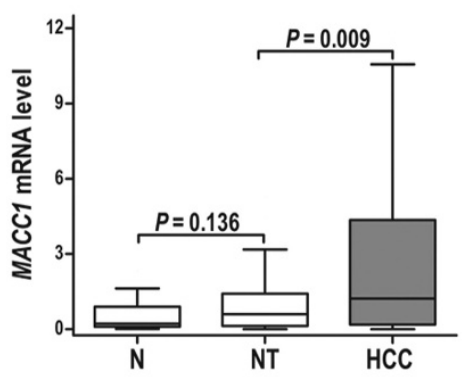

Figure 1 Analysis of $\mathbf{M A C C} 1$ expression in liver tissues and cell lines. A: MACC1 expression in four human hepatoma cell lines (HepG2, SMMC-7721, MHCC-97H, and MHCC-97L) and one normal liver cell line, L-02, by reverse-transcription PCR (RT-PCR). B: Representative MACC1 mRNA expression in hepatocellular carcinomas (T) and matching non-cancerous (NT) and normal non-cirrhosis (N) liver tissue using RT-PCR. An RT-negative control (-) was added to rule out false positives resulting from contaminated DNA. Products of 136 bp were expected for MACC1 transcripts. C: Comparison of MACC1 expression levels in five liver cell lines, as determined by real-time quantitative-PCR (Q-PCR). D: Comparison of MACC1 expression levels in 20 normal liver tissues (N), and 128 paired HCC with matching non-cancerous (NT) specimens by Q-PCR. The differences among HCC tissues (median 1.632), the adjacent non-cancerous tissues (median 0.601), and normal tissues (median 0.218) are significant $(P=0.009, P=0.008$, respectively), and no significant difference was found between the adjacent non-cancerous and normal tissues $(P=0.136)$.
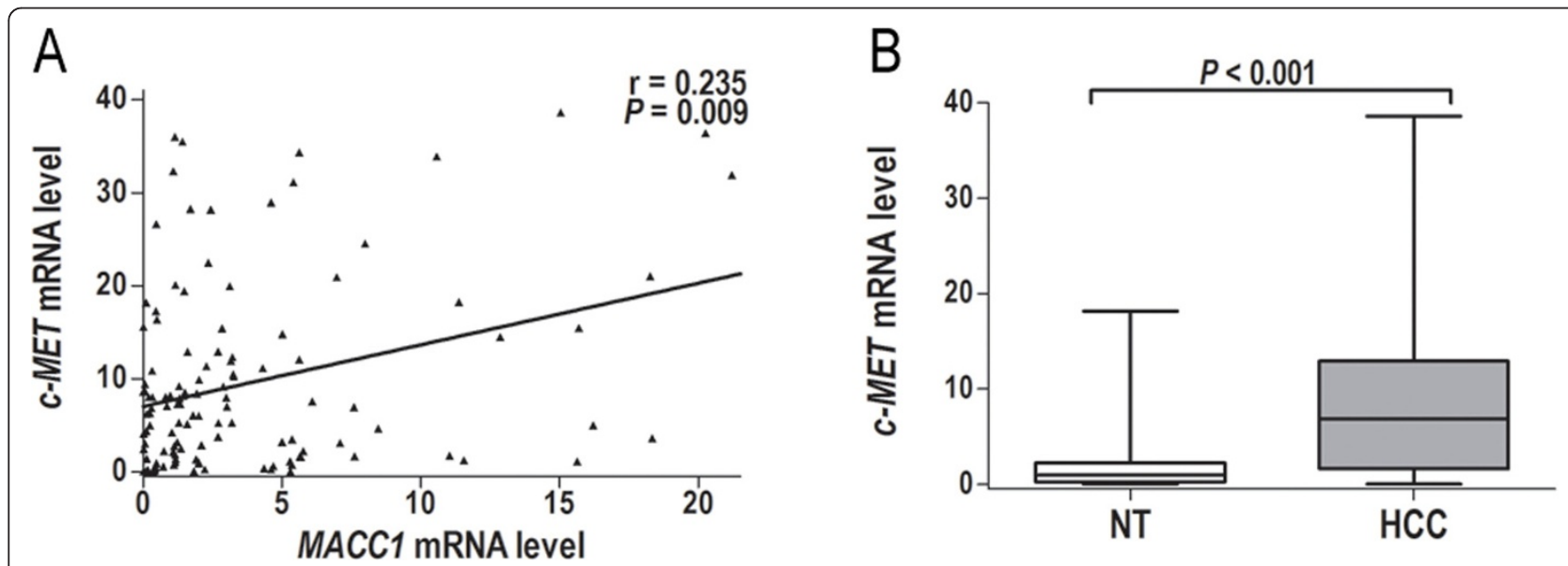

Figure 2 c-MET expression and correlation with MACC1 in 128 paired HCC specimens: A MACC1 levels from 128 HCC specimens were plotted against c-MET levels from the same patients. Linear regression analysis showed a significant positive correlation between MACC1 and C-MET $(r=0.567, P=0.001)$. B Comparison of $c-M E T$ expression levels in 128 HCC specimens. The difference between HCC tissues and the adjacent non-cancerous tissues (NT) is significant $(P<0.001)$. 
PCR and conventional RT-PCR results could have occurred because conventional PCR analysis is more inclined to be influenced by PCR reaction conditions. MACC1 mRNA expression was significantly associated with preoperative serum AFP level using Q-PCR analysis. High MACC1 expression was more frequent in high-AFP HCC patients $(P=0.025)$. No relationship was found between the expression of $M A C C 1$ and other clinicopathological variables, including gender, age, hepatitis $B$ surface antigen (HBsAg) status, liver cirrhosis, TNM stage, tumour size, tumour number, tumour capsule, vascular invasion, and Edmondson-Steiner grade (Table 1).

\section{Prognostic of HCC subtypes defined by MACC1 level}

Significant OS and DFS advantages were observed for the patients with low MACC1 mRNA. The 5-year OS rate of the low-level group was $61.9 \%$, which was significantly higher than that of the high-level group $(37.6 \%, P$ $=0.003)$. The 5-year DFS rate of the low-level group was $54.5 \%$, which was significantly higher than that of the high-level group (33.5\%, $P=0.008$ ) (Figure 3). The associations of OS and DFS with clinicopathological variables in our 128 cases of HCC are shown in Table 2. In a multivariate analysis model, $M A C C 1$ remained significantly associated with OS (HR 2.230; 95\% CI, 1.2573.957; $P=0.006)$ and DFS (HR 1.687; 95\% CI, 1.0342.751; $P=0.036$ ) (Table 3). Low MACC1 indicates longer distant metastasis-free survival (MFS) for colon cancer patients[22]. However, no such correlation was found between MACC1 expression and MFS among these HCC patients $(P=0.803)$.

\section{Stratified univariate and multivariate analysis}

Because survival might be associated with the pathological TNM stage, we stratified the data according to TNM stage and investigated the prognostic value of $M A C C 1$ in different stages. For the 67 TNM stage I patients, significant correlations were found between MACC1 expression and OS $(P=0.021)$ and DFS $(P=0.017)$ (Figure 4). MACC1 had no prognostic value regarding OS or DFS for patients with TNM stage II or III (all $P$ $>0.05)$. The associations of OS and DFS with clinicopathological features in TNM stage I HCC are shown in Table 4. In the Cox model adjusting for other prognostic variables, $M A C C 1$ was an independent negative prognostic factor for survival in TNM stage I patients (Table 5). Patients with high $M A C C 1$ expression had poorer OS (HR 2.643; 95\% CI, 1.103-6.329; $P=0.029$ ) and DFS (HR 3.316; 95\% CI, 1.012-10.859; $P=0.048$ ) than those with low MACC1 expression in TNM stage I.

\section{Discussion}

The transcript levels of $M A C C 1$ in normal liver tissue are $14 \times 10^{6}$, as detected by expressed sequence tags
Table 1 Correlations between MACC1 mRNA expression and clinicopathologic features of HCC

\begin{tabular}{|c|c|c|c|}
\hline Characteristics & $\begin{array}{c}\text { No. } \\
\text { patients }\end{array}$ & $\begin{array}{c}\text { MACC1 mRNA high } \\
\text { level }\end{array}$ & $\begin{array}{c}P \\
\text { value* }\end{array}$ \\
\hline \multicolumn{4}{|l|}{ Gender } \\
\hline Female & 12 & $58.3 \%(7 / 12)$ & 0.169 \\
\hline Male & 116 & $37.9 \%(44 / 116)$ & \\
\hline \multicolumn{4}{|l|}{ Age (years) ${ }^{\dagger}$} \\
\hline$\leq 50$ & 65 & $44.6 \%(29 / 65)$ & 0.263 \\
\hline$>50$ & 63 & $34.9 \%(22 / 63)$ & \\
\hline \multicolumn{4}{|l|}{ HBsAg status } \\
\hline Negative & 18 & $33.3 \%(6 / 18)$ & 0.543 \\
\hline Positive & 110 & $40.9 \%(45 / 110)$ & \\
\hline \multicolumn{4}{|l|}{ AFP $(\mu \mathrm{g} / \mathrm{l})$} \\
\hline$\leq 400$ & 78 & $32.1 \%(25 / 78)$ & 0.025 \\
\hline$>400$ & 50 & $52.0 \%(26 / 50)$ & \\
\hline \multicolumn{4}{|l|}{ Cirrhosis } \\
\hline No & 13 & $30.8 \%(4 / 13)$ & 0.481 \\
\hline Yes & 115 & $40.9 \%(47 / 115)$ & \\
\hline \multicolumn{4}{|c|}{ Child-Pugh classification $^{\ddagger}$} \\
\hline A & 116 & $39.7 \%(46 / 116)$ & 0.892 \\
\hline$B$ & 12 & $41.7 \%(5 / 12)$ & \\
\hline \multicolumn{4}{|l|}{ Tumour size $(\mathrm{cm})$} \\
\hline$\leq 5$ & 50 & $40.0 \%(20 / 50)$ & 0.977 \\
\hline$>5$ & 78 & $39.7 \%(31 / 78)$ & \\
\hline \multicolumn{4}{|l|}{ Multiple tumours } \\
\hline No & 91 & $39.6 \%(36 / 91)$ & 0.918 \\
\hline Yes & 37 & $40.5 \%(15 / 37)$ & \\
\hline \multicolumn{4}{|l|}{ Tumour capsule } \\
\hline Complete & 32 & $34.4 \%(11 / 32)$ & 0.466 \\
\hline $\begin{array}{l}\text { No/ } \\
\text { incomplete }\end{array}$ & 96 & $41.7 \%(40 / 96)$ & \\
\hline \multicolumn{4}{|l|}{ Vascular invasion } \\
\hline No & 98 & $37.8 \%(37 / 98)$ & 0.383 \\
\hline Yes & 30 & $46.7 \%(14 / 30)$ & \\
\hline \multicolumn{4}{|c|}{ Edmondson-Steiner grade } \\
\hline$|/| \mid$ & 69 & $34.8 \%(24 / 69)$ & 0.206 \\
\hline III/IV & 59 & $39.8 \%(27 / 59)$ & \\
\hline \multicolumn{4}{|l|}{ TNM stage } \\
\hline 1 & 67 & $31.3 \%(21 / 67)$ & 0.077 \\
\hline$\|$ & 26 & $42.3 \%(11 / 26)$ & \\
\hline III & 35 & $54.3 \%(19 / 31)$ & \\
\hline
\end{tabular}

MACC1, metastasis-associated in colon cancer-1; HCC, hepatocellular carcinoma; $A F P$, $\alpha$-fetoprotein; $H B s A g$, hepatitis B surface antigen. ${ }^{*}$ Chi-square or Fisher's exact test.

${ }^{\dagger}$ Patients were divided according to the median age.

${ }^{\ddagger}$ No patients with Child-Pugh $C$ were included.

(ESTs), compared with $20 \times 10^{6}$ in malignant liver tissue, according to the EST profile viewer of the NCBI UniGene database http://www.ncbi.nlm.gov/UniGene. These were supported by our study and another paper published recently. Shirahata et al. [29] showed that $M A C C 1$ expression was significantly correlated with vascular invasion and serum AFP level. However, with their 

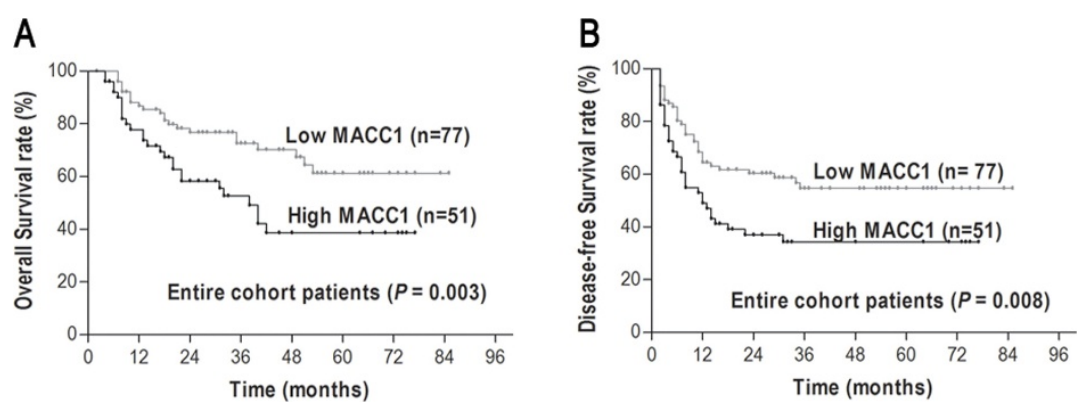

Figure 3 Kaplan-Meier survival curves according to MACC1 expression in $128 \mathrm{HCC}$ patients: A Overall survival (log-rank $P=0.003)$. B Disease-free survival (log-rank $P=0.008$ ).

Table 2 Univariate prognostic analysis of overall survival and disease-free survival in HCC patients

\begin{tabular}{|c|c|c|c|c|c|c|}
\hline \multirow[t]{2}{*}{ Variable } & \multicolumn{3}{|c|}{ Overall survival rate (\%) } & \multicolumn{3}{|c|}{ Disease-free survival rate (\%) } \\
\hline & $3 y$ & $5 y$ & $P$ value & $3 y$ & $5 y$ & $P$ value \\
\hline \multicolumn{7}{|l|}{ Gender } \\
\hline Female $(n=12)$ & 91.3 & 61.8 & 0.328 & 66.7 & 66.7 & 0.176 \\
\hline Male $(n=116)$ & 61.9 & 51.0 & & 43.8 & 43.8 & \\
\hline \multicolumn{7}{|l|}{ Age (years) } \\
\hline$\leq 50(n=65)$ & 62.5 & 52.2 & 0.567 & 42.7 & 42.7 & 0.101 \\
\hline$>50(n=63)$ & 67.0 & 51.9 & & 49.4 & 49.4 & \\
\hline \multicolumn{7}{|l|}{ HBsAg status } \\
\hline Negative $(n=18)$ & 88.5 & 62.1 & 0.122 & 71.8 & 71.8 & 0.027 \\
\hline Positive $(n=110)$ & 60.5 & 49.7 & & 41.9 & 41.9 & \\
\hline \multicolumn{7}{|l|}{$\operatorname{AFP}(\mu \mathrm{g} / \mathrm{l})$} \\
\hline$\leq 400(n=78)$ & 59.3 & 47.7 & 0.219 & 44.3 & 44.3 & 0.555 \\
\hline$>400(n=50)$ & 75.0 & 59.8 & & 50.9 & 50.9 & \\
\hline \multicolumn{7}{|l|}{ Cirrhosis } \\
\hline No $(n=13)$ & 91.7 & 80.2 & 0.053 & 54.9 & 54.9 & 0.184 \\
\hline Yes $(n=115)$ & 61.3 & 48.1 & & 44.6 & 44.6 & \\
\hline \multicolumn{7}{|l|}{ Child-Pugh classification } \\
\hline $\mathrm{A}(n=116)$ & 65.4 & 55.0 & 0.378 & 48.8 & 48.8 & 0.154 \\
\hline $\mathrm{B}(n=12)$ & 58.3 & 29.2 & & 20.8 & 20.8 & \\
\hline \multicolumn{7}{|l|}{ Tumour size $(\mathrm{cm})$} \\
\hline$\leq 5(n=50)$ & 81.7 & 77.3 & $<0.001$ & 72.1 & 72.1 & $<0.001$ \\
\hline$>5(n=78)$ & 52.6 & 36.3 & & 29.2 & 29.2 & \\
\hline \multicolumn{7}{|l|}{ Multiple tumours } \\
\hline No $(n=91)$ & 70.0 & 60.4 & 0.002 & 56.5 & 56.5 & $<0.001$ \\
\hline Yes $(n=37)$ & 49.3 & 30.2 & & 19.8 & 19.8 & \\
\hline \multicolumn{7}{|l|}{ Tumour capsule } \\
\hline Complete $(n=32)$ & 71.2 & 71.2 & 0.165 & 61.1 & 61.1 & 0.096 \\
\hline No/incomplete $(n=96)$ & 62.5 & 46.4 & & 41.0 & 41.0 & \\
\hline \multicolumn{7}{|l|}{ Vascular invasion } \\
\hline No $(n=98)$ & 71.7 & 65.3 & $<0.001$ & 54.2 & 54.2 & $<0.001$ \\
\hline Yes $(n=30)$ & 40.8 & 11.6 & & 19.4 & 19.4 & \\
\hline \multicolumn{7}{|l|}{ TNM stage } \\
\hline I $(n=67)$ & 79.3 & 72.1 & $<0.001$ & 64.7 & 64.7 & $<0.001$ \\
\hline$\|(n=30)$ & 54.9 & 38.4 & & 30.8 & 30.8 & \\
\hline III $(n=31)$ & 42.0 & 22.5 & & 20.7 & 20.7 & \\
\hline \multicolumn{7}{|l|}{ Edmondson-Steiner grade } \\
\hline$|/| \mid(n=69)$ & 75.9 & 63.0 & 0.004 & 56.7 & 56.7 & 0.003 \\
\hline III/IV $(n=59)$ & 50.6 & 38.4 & & 33.4 & 33.4 & \\
\hline \multicolumn{7}{|l|}{ MACC1 expression level } \\
\hline Low $(n=71)$ & 73.5 & 61.9 & 0.003 & 54.5 & 54.5 & 0.008 \\
\hline High $(n=57)$ & 51.8 & 37.6 & & 33.5 & 33.5 & \\
\hline
\end{tabular}


Table 3 Multivariate analysis of factors contributing to overall survival and disease-free survival in HCC patients

\begin{tabular}{lcccc}
\hline Variable & \multicolumn{2}{c}{ Overall survival } & \multicolumn{2}{c}{ Disease-free survival } \\
\cline { 2 - 5 } & HR (95\% Cl) & P value & HR (95\% Cl) & P value \\
\hline Tumour size & $3.008(1.315-6.881)$ & 0.009 & $3.227(1.664-6.260)$ & 0.001 \\
Multiple tumours & $1.361(0.614-3.017)$ & 0.447 & $2.254(1.175-4.326)$ & 0.014 \\
Vascular invasion & $2.280(1.140-4.561)$ & 0.020 & $1.873(1.002-3.545)$ & 0.049 \\
HBsAg status & - & - & $2.922(1.153-7.403)$ & 0.024 \\
Edmondson-Steiner grade & $1.853(1.016-3.379)$ & 0.044 & $1.615(0.964-2.705)$ & 0.068 \\
TNM stage & $1.136(0.650-1.985)$ & 0.654 & $0.865(0.546-1.369)$ & 0.535 \\
MACC1 expression level & $2.230(1.257-3.957)$ & 0.006 & $1.687(1.034-2.751)$ & 0.036 \\
\hline
\end{tabular}

MACC1, metastasis-associated in colon cancer-1; HCC, hepatocellular carcinoma; $H B S A g$, hepatitis B surface antigen; $H R$, hazard ratio; $C l$, confidence interval.

small number of HCC patients $(\mathrm{n}=30)$, statistical power was limited, and the authors did not explore its clinical predictive value for HCC patients. In this study, we analysed the mRNA expression of MACC1 in a relatively large population of HCC patients and correlated it with clinicopathological features and prognosis to determine whether this biomarker could predict disease outcomes. MACC1 expression in HCC tissue was significantly higher than in nonmalignant tissue. Importantly, high MACC1 expression was significantly correlated with more aggressive behaviour in terms of shorter OS and DFS and higher serum AFP, which is a putative clinicopathologic marker of HCC invasiveness and unfavourable prognosis [30]. These data indicate that high $M A C C 1$ expression occurs in HCC and is associated with an aggressive invasion phenotype. Although elevated MACC1 expression was associated with high AFP in our study, which agrees with the data of Shirahata et al., no significant correlation has been observed between vascular invasion and $M A C C 1$ expression. This disparity presumably stems from different sample sizes and heterogeneity of study populations, which led to the relatively low proportion (4/30) of vascular invasion in the study of Shirahat's group [29]. Stein et al. observed that high MACC1 levels indicated poor MFS for colon cancer. In contrast to colon cancer, intrahepatic metastasis is the most frequent pattern in the progression of HCC $[5,31]$, which may partially explain why no such relationship was found in this study. However, it is difficult to define whether intrahepatic recurrence after hepatectomy originates from either residual intrahepatic metastasis or metachronous multicentric carcinogenesis $[32,33]$. Because the number of extrahepatic metastasis cases was limited in this study $(\mathrm{n}=18)$, future studies are needed to address this issue more definitively.

Because MACC1 may promote cell migration and invasion by upregulating the downstream c-MET gene in colon cancer [22], we sought to determine whether such a mechanism might contribute to the increased invasiveness of HCC induced by MACC1. This study found a positive association between $M A C C 1$ and cMET mRNA levels in HCC. This might support the existence of a regulatory and functional relationship between MACC1 and c-MET [34,35]. Furthermore, based on c-MET contributes to the aggressiveness of HCC [17], this correlation might further indicate that MACC1 enhances the invasiveness of liver cancer cells.

Our study shows that $M A C C 1$ was expressed highly in HCC samples and cultured cancer cell lines. The mechanism of this high expression is still unclear, but it is interesting to note that chromosome region $7 \mathrm{p} 21$, which contains the MACC1 gene [36], frequently
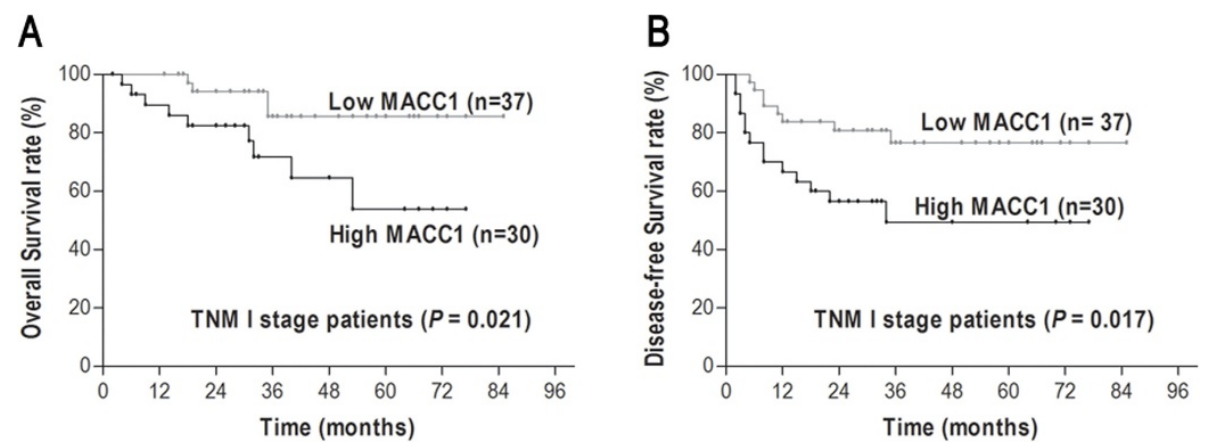

Figure 4 Kaplan-Meier curves according to MACC1 expression in TNM stage I HCC patients: A Overall survival (log-rank $P=0.021)$, B Disease-free survival (log-rank $P=0.017)$. 
Table 4 Univariate prognostic analysis of overall survival and disease-free survival in TNM stage I HCC patients

\begin{tabular}{|c|c|c|c|c|c|c|}
\hline \multirow[t]{2}{*}{ Variables } & \multicolumn{3}{|c|}{ Overall survival rate (\%) } & \multicolumn{3}{|c|}{ Disease-free survival rate (\%) } \\
\hline & $3 y$ & $5 y$ & $P$ value & $3 y$ & $5 y$ & $P$ value \\
\hline \multicolumn{7}{|l|}{ Gender } \\
\hline Female $(n=9)$ & 100.0 & 81.8 & 0.438 & 77.8 & 77.8 & 0.473 \\
\hline Male $(n=58)$ & 75.7 & 71.1 & & 62.3 & 62.3 & \\
\hline \multicolumn{7}{|l|}{ Age (years) } \\
\hline$\leq 50(n=32)$ & 87.4 & 80.4 & 0.213 & 71.3 & 71.3 & 0.560 \\
\hline$>50(n=35)$ & 73.0 & 65.7 & & 59.4 & 59.4 & \\
\hline \multicolumn{7}{|l|}{ HBsAg status } \\
\hline Negative $(n=13)$ & 83.9 & 83.9 & 0.752 & 76.2 & 76.2 & 0.426 \\
\hline Positive $(n=54$ & 78.2 & 69.4 & & 62.1 & 62.1 & \\
\hline \multicolumn{7}{|l|}{$\operatorname{AFP}(\mu \mathrm{g} / \mathrm{l})$} \\
\hline$\leq 400(n=43)$ & 71.0 & 65.3 & 0.199 & 62.1 & 62.1 & 0.690 \\
\hline$>400(n=24)$ & 91.1 & 82.8 & & 68.0 & 68.0 & \\
\hline \multicolumn{7}{|l|}{ Cirrhosis } \\
\hline No $(n=8)$ & 100.0 & 100.0 & 0.128 & 75.0 & 75.0 & 0.565 \\
\hline Yes $(n=59)$ & 76.0 & 67.5 & & 63.2 & 63.2 & \\
\hline \multicolumn{7}{|l|}{ Child-Pugh classification } \\
\hline $\mathrm{A}(n=61)$ & 78.9 & 75.5 & 0.499 & 67.2 & 67.2 & 0.519 \\
\hline $\mathrm{B}(n=6)$ & 83.3 & 55.6 & & 44.4 & 44.4 & \\
\hline \multicolumn{7}{|l|}{ Tumour size $(\mathrm{cm})$} \\
\hline$\leq 5(n=40)$ & 82.6 & 82.6 & 0.061 & 77.7 & 77.7 & 0.006 \\
\hline$>5(n=27)$ & 73.0 & 57.0 & & 45.7 & 45.7 & \\
\hline \multicolumn{7}{|l|}{ Tumour capsule } \\
\hline Complete $(n=26)$ & 81.0 & 81.0 & 0.787 & 67.3 & 67.3 & 0.957 \\
\hline No/incomplete $(n=41)$ & 79.1 & 68.3 & & 63.3 & 63.3 & \\
\hline \multicolumn{7}{|l|}{ Edmondson-Steiner grade } \\
\hline$|/| \mid(n=46)$ & 80.9 & 80.9 & 0.172 & 68.3 & 68.3 & 0.338 \\
\hline III/IV $(n=21)$ & 73.7 & 60.0 & & 57.1 & 57.1 & \\
\hline \multicolumn{7}{|l|}{ MACC1 expression level } \\
\hline Low $(n=37)$ & 85.6 & 85.6 & 0.021 & 76.5 & 76.5 & 0.017 \\
\hline High $(n=30)$ & 71.1 & 53.3 & & 49.4 & 49.4 & \\
\hline
\end{tabular}

MACC1, metastasis-associated in colon cancer-1; HCC, hepatocellular carcinoma; $A F P, \alpha$-fetoprotein; $H B s A g$, hepatitis B surface antigen.

exhibits aberrant amplification of expression in HCC [37-39].

We hypothesised that high expression of $M A C C 1$ was causally associated with HCC invasion, based on several lines of evidence. First, we have shown that high $M A C C 1$ expression in human $\mathrm{HCC}$ was associated with

Table 5 Multivariate analysis of factors contributing to overall survival and disease-free survival in TNM stage I HCC patients

\begin{tabular}{|c|c|c|c|c|}
\hline \multirow[t]{2}{*}{ Variable } & \multicolumn{2}{|c|}{ Overall survival } & \multicolumn{2}{|c|}{ Disease-free survival } \\
\hline & HR $(95 \% \mathrm{Cl})$ & $\begin{array}{c}P \\
\text { value }\end{array}$ & HR $(95 \% \mathrm{Cl})$ & $\begin{array}{c}P \\
\text { value }\end{array}$ \\
\hline Tumour size & $\begin{array}{l}3.062(1.280- \\
7.323)\end{array}$ & 0.012 & $\begin{array}{l}2.445(0.794- \\
7.532)\end{array}$ & 0.119 \\
\hline $\begin{array}{l}\text { MACC1 expression } \\
\text { level }\end{array}$ & $\begin{array}{l}2.643(1.103- \\
\quad 6.329)\end{array}$ & 0.029 & $\begin{array}{l}3.316(1.012- \\
10.859)\end{array}$ & 0.048 \\
\hline
\end{tabular}

MACC1, metastasis-associated in colon cancer-1; HCC, hepatocellular carcinoma; $\mathrm{HR}$, hazard ratio; $\mathrm{Cl}$, confidence interval. higher serum AFP and shorter OS and DFS. Second, the level of MACC1 mRNA was high in MHCC-97H cells (Figure 1C), which are derived from the high-metastasispotential cell line MHCC97 [40]. Third, the level of $M A C C 1$ was positively correlated with that of c-MET, which plays critical roles in cancer cell migration and metastasis. Because this study enrolled mostly hepatitis $B$ virus-dependent $\mathrm{HCC}$ patients (85.9\%), it remains to be studied whether MACC1 as a marker of aggressive phenotype can be extended to HCC cases resulting from other aetiologies. Hepatitis virus-dependent and alcoholdependent HCC display overexpression of MYC, whereas nonalcoholic steatohepatitis may evolve into malignancy via a MYC-independent mechanism, indicating that the existence of genetic discrepancies may occur via different aetiological routes [41]. Whether $M A C C 1$ is associated with certain aetiological factors needs to be further investigated. 
Clinical stage is the most important factor influencing the prognosis of HCC patients. Several systems are available to classify HCC. Among them, the International Union Against Cancer's TNM staging is one of the most prevalent. Although the TNM system has successfully graded patients on their prognosis according to clinicopathological variables, it has reached its limit in providing critical information that may influence treatment strategy. It is difficult for liver surgeons to predict exactly which individuals will experience relapse among early-stage patients who have undergone curative treatment. To overcome the limitations of these traditional systems, many molecular markers have been investigated and shown to have potential predictive significance. However, to date, biomarkers that could stratify HCC patients with curative excision in TNM stage I are still substantially limited. In our stratified analysis, we found that MACC1 mRNA expression had clear prognostic value for OS and DFS in TNM stage I patients. These data imply that MACC1 mRNA might act as a predictive tool to identify patients with TNM stage I at high risk of recurrence.

MACC1 may act as a key regulator of the HGF/cMET pathway, leading to distant metastases in colon cancer [22]. The relationships of MACC1 with other signalling molecules and pathways must be further evaluated to better understand the molecular pathogenesis of these tumours and develop more effective targeted therapeutic strategies.

\section{Conclusion}

This study established a correlation between MACC1 expression and $\mathrm{HCC}$ prognosis. MACC1 was highly expressed in $\mathrm{HCC}$ tissues and predicted the prognosis of HCC patients, suggesting MACC1 may be involved in the HCC malignant process. This information can be used to identify high-risk HCC patients who may benefit from more intensive treatment and follow-up care after resection of primary tumours. It also justifies further studies to gain insight into the underlying biology of MACC1 and to strive for a positive response after administration of innovative therapies targeted at MACC1.

\footnotetext{
List of abbreviations

HCC: hepatocellular carcinoma; RT-PCR: reverse-transcription polymerase chain reaction; Q-PCR: real-time quantitative PCR; CDNA: complementary DNA; MACC1: metastasis-associated in colon cancer-1; HGF: hepatocyte growth factor; c-MET: c-MET proto-oncogene; AFP: alpha fetoprotein; TNM: tumour-node-metastasis; OS: overall survival; DFS: disease-free survival; MFS: metastasis-free survival.
}

\section{Acknowledgements}

This work was supported by grants from the National Natural Science Foundation of China (30872489 and 30972916). The authors thank all the patients who participated in this study.

\section{Author details}

${ }^{1}$ State Key Laboratory of Oncology in South China/Department of Hepatobiliary Oncology, Sun Yat-sen University Cancer Center, Guangzhou, China. ${ }^{2}$ Department of Surgery, the First Affiliated Hospital, Gannan Medical College, Ganzhou, China. ${ }^{3}$ Department of General Surgery, Beijing Shijitan Hospital, Beijing, China. ${ }^{4}$ Department of Surgery, the Sixth Affiliated Hospital, Sun Yat-sen University, Guangzhou, China.

\section{Authors' contributions}

YFY and JPW were responsible for the design of this study. JLQ conducted the experiments and drafted the manuscript. $\mathrm{PZH}$ participated in the data analysis. CLL and LW helped in sample collection. QL, JH and BKL helped in amending the manuscript. All authors read and approved the final manuscript.

\section{Competing interests}

The authors declare that they have no competing interests.

Received: 14 May 2011 Accepted: 29 September 2011

Published: 29 September 2011

\section{References}

1. Parkin DM, Bray F, Ferlay J, Pisani P: Global cancer statistics, 2002. CA Cancer J Clin 2005, 55:74-108.

2. El-Serag HB, Rudolph KL: Hepatocellular carcinoma: epidemiology and molecular carcinogenesis. Gastroenterology 2007, 132:2557-2576.

3. Altekruse SF, McGlynn KA, Reichman ME: Hepatocellular carcinoma incidence, mortality, and survival trends in the United States from 1975 to 2005. J Clin Oncol 2009, 27:1485-1491.

4. Jemal A, Siegel R, Ward E, Hao Y, Xu J, Thun MJ: Cancer statistics, 2009. CA Cancer J Clin 2009, 59:225-249.

5. Llovet JM, Burroughs A, Bruix J: Hepatocellular carcinoma. Lancet 2003, 362:1907-1917.

6. Yang LY, Fang F, Ou DP, Wu W, Zeng ZJ, Wu F: Solitary large hepatocellular carcinoma: a specific subtype of hepatocellular carcinoma with good outcome after hepatic resection. Ann Surg 2009, 249:118-123.

7. Cherqui D, Laurent A, Mocellin N, Tayar C, Luciani A, Van Nhieu JT, Decaens T, Hurtova M, Memeo R, Mallat A, Duvoux C: Liver resection for transplantable hepatocellular carcinoma: long-term survival and role of secondary liver transplantation. Ann Surg 2009, 250:738-746.

8. Aravalli RN, Steer CJ, Cressman EN: Molecular mechanisms of hepatocellular carcinoma. Hepatology 2008, 48:2047-2063.

9. Dragani TA: Risk of HCC: genetic heterogeneity and complex genetics. $J$ Hepatol 2010, 52:252-257.

10. Ma WW, Adjei AA: Novel agents on the horizon for cancer therapy. CA Cancer J Clin 2009, 59:111-137.

11. Llovet JM, Bruix J: Molecular targeted therapies in hepatocellular carcinoma. Hepatology 2008, 48:1312-1327.

12. Villanueva A, Chiang DY, Newell P, Peix J, Thung S, Alsinet C, Tovar V, Roayaie S, Minguez B, Sole M, Battiston C, Van Laarhoven S, Fiel MI, Di Feo A, Hoshida Y, Yea S, Toffanin S, Ramos A, Martignetti JA, Mazzaferro V, Bruix J, Waxman S, Schwartz M, Meyerson M, Friedman SL, Llovet JM: Pivotal role of mTOR signaling in hepatocellular carcinoma. Gastroenterology 2008, 135:1972-1983, 1983 e1971-1911.

13. Clevers $\mathrm{H}$ : Wnt/beta-catenin signaling in development and disease. Cell 2006, 127:469-480.

14. Lai AZ, Abella JV, Park M: Crosstalk in Met receptor oncogenesis. Trends Cell Biol 2009, 19:542-551.

15. Ponzo MG, Lesurf $R$, Petkiewicz $S$, O'Malley FP, Pinnaduwage $D$, Andrulis $I L$, Bull SB, Chughtai N, Zuo D, Souleimanova M, Germain D, Omeroglu A, Cardiff RD, Hallett M, Park M: Met induces mammary tumors with diverse histologies and is associated with poor outcome and human basal breast cancer. Proc Natl Acad Sci USA 2009, 106:12903-12908.

16. Cappuzzo F, Marchetti A, Skokan M, Rossi E, Gajapathy S, Felicioni L, Del Grammastro M, Sciarrotta MG, Buttitta F, Incarbone M, Toschi L, Finocchiaro G, Destro A, Terracciano L, Roncalli M, Alloisio M, Santoro A, Varella-Garcia M: Increased MET gene copy number negatively affects survival of surgically resected non-small-cell lung cancer patients. J Clin Oncol 2009, 27:1667-1674.

17. Kaposi-Novak P, Lee JS, Gomez-Quiroz L, Coulouarn C, Factor VM, Thorgeirsson SS: Met-regulated expression signature defines a subset of 
human hepatocellular carcinomas with poor prognosis and aggressive phenotype. J Clin Invest 2006, 116:1582-1595.

18. Liu X, Newton RC, Scherle PA: Developing c-MET pathway inhibitors for cancer therapy: progress and challenges. Trends Mol Med 2010, 16:37-45.

19. Engelman JA, Zejnullahu K, Mitsudomi T, Song Y, Hyland C, Park JO, Lindeman N, Gale CM, Zhao X, Christensen J, Kosaka T, Holmes AJ, Rogers AM, Cappuzzo F, Mok T, Lee C, Johnson BE, Cantley LC, Janne PA: MET amplification leads to gefitinib resistance in lung cancer by activating ERBB3 signaling. Science 2007, 316:1039-1043.

20. Nathan H, Schulick RD, Choti MA, Pawlik TM: Predictors of survival after resection of early hepatocellular carcinoma. Ann Surg 2009, 249:799-805.

21. Kim BK, Han KH, Park YN, Park MS, Kim KS, Choi JS, Moon BS, Chon CY, Moon YM, Ahn SH: Prediction of microvascular invasion before curative resection of hepatocellular carcinoma. J Surg Oncol 2008, 97:246-252.

22. Stein $U$, Walther W, Arlt F, Schwabe H, Smith J, Fichtner I, Birchmeier W, Schlag PM: MACC1, a newly identified key regulator of HGF-MET signaling, predicts colon cancer metastasis. Nat Med 2009, 15:59-67.

23. Sobin $L H$, Wittekind C: International Union Against Cancer. TNM classification of malignant tumors. 6 edition. New York: John Wiley \& Sons; 2002.

24. Shi M, Guo RP, Lin XJ, Zhang YQ, Chen MS, Zhang CQ, Lau WY, Li JQ: Partial hepatectomy with wide versus narrow resection margin for solitary hepatocellular carcinoma: a prospective randomized trial. Ann Surg 2007, 245:36-43.

25. Tang SH, Yang DH, Huang W, Zhou HK, Lu XH, Ye G: Hypomethylated P4 promoter induces expression of the insulin-like growth factor-ll gene in hepatocellular carcinoma in a Chinese population. Clin Cancer Res 2006, 12:4171-4177.

26. Huang P, Qiu J, Li B, Hong J, Lu C, Wang L, Wang J, Hu Y, Jia W, Yuan Y: Role of Sox2 and Oct4 in predicting survival of hepatocellular carcinoma patients after hepatectomy. Clin Biochem 2011, 44:582-589.

27. Schmittgen TD, Livak KJ: Analyzing real-time PCR data by the comparative C(T) method. Nat Protoc 2008, 3:1101-1108.

28. Mazumdar M, Smith A, Bacik J: Methods for categorizing a prognostic variable in a multivariable setting. Stat Med 2003, 22:559-571.

29. Shirahata A, Fan W, Sakuraba K, Yokomizo K, Goto T, Mizukami H, Saito M, Ishibashi K, Kigawa G, Nemoto H, Sanada Y, Hibi K: MACC 1 as a marker for vascular invasive hepatocellular carcinoma. Anticancer Res 2011, 31:777-780.

30. Peng SY, Chen WJ, Lai PL, Jeng YM, Sheu JC, Hsu HC: High alphafetoprotein level correlates with high stage, early recurrence and poor prognosis of hepatocellular carcinoma: significance of hepatitis virus infection, age, p53 and beta-catenin mutations. Int J Cancer 2004, $112: 44-50$

31. Katyal S, Oliver JH, Peterson MS, Ferris JV, Carr BS, Baron RL: Extrahepatic metastases of hepatocellular carcinoma. Radiology 2000, 216:698-703.

32. Sakon M, Umeshita K, Nagano H, Eguchi H, Kishimoto S, Miyamoto A, Ohshima S, Dono K, Nakamori S, Gotoh M, Monden M: Clinical significance of hepatic resection in hepatocellular carcinoma: analysis by disease-free survival curves. Arch Surg 2000, 135:1456-1459.

33. Kawano Y, Sasaki A, Kai S, Endo Y, Iwaki K, Uchida H, Shibata K, Ohta M, Kitano S: Prognosis of patients with intrahepatic recurrence after hepatic resection for hepatocellular carcinoma: a retrospective study. Eur J Surg Oncol 2009, 35:174-179.

34. Stein U, Smith J, Walther W, Arlt F: MACC1 controls Met: what a difference an Sp1 site makes. Cell Cycle 2009, 8:2467-2469.

35. Arlt F, Stein U: Colon cancer metastasis: MACC1 and Met as metastatic pacemakers. Int J Biochem Cell Biol 2009, 41:2356-2359.

36. Stein U, Dahlmann M, Walther W: MACC1 - more than metastasis? Facts and predictions about a novel gene. J Mol Med 2010, 88:11-18.

37. Sun $T$, Zhao N, Zhao XL, Gu Q, Zhang SW, Che N, Wang XH, Du J, Liu YX, Sun BC: Expression and functional significance of Twist1 in hepatocellular carcinoma: its role in vasculogenic mimicry. Hepatology 2010, 51:545-556.

38. Zimoniic DB, Keck CL, Thorgeirsson SS, Popescu NC: Novel recurrent genetic imbalances in human hepatocellular carcinoma cell lines identified by comparative genomic hybridization. Hepatology 1999, 29:1208-1214.

39. Calvisi DF, Pinna F, Ladu S, Pellegrino R, Simile MM, Frau M, De Miglio MR, Tomasi ML, Sanna V, Muroni MR, Feo F, Pascale RM: Forkhead box M1B is a determinant of rat susceptibility to hepatocarcinogenesis and sustains ERK activity in human HCC. Gut 2009, 58:679-687.

40. Tian J, Tang ZY, Ye SL, Liu YK, Lin ZY, Chen J, Xue Q: New human hepatocellular carcinoma (HCC) cell line with highly metastatic potential (MHCC97) and its expressions of the factors associated with metastasis. Br J Cancer 1999, 81:814-821.

41. Schlaeger $C$, Longerich $T$, Schiller $C$, Bewerunge P, Mehrabi A, Toedt G, Kleeff J, Ehemann V, Eils R, Lichter P, Schirmacher P, Radlwimmer B: Etiology-dependent molecular mechanisms in human hepatocarcinogenesis. Hepatology 2008, 47:511-520.

doi:10.1186/1479-5876-9-166

Cite this article as: Qiu et al: Identification of MACC1 as a novel prognostic marker in hepatocellular carcinoma. Journal of Translational Medicine 2011 9:166.

\section{Submit your next manuscript to BioMed Central and take full advantage of:}

- Convenient online submission

- Thorough peer review

- No space constraints or color figure charges

- Immediate publication on acceptance

- Inclusion in PubMed, CAS, Scopus and Google Scholar

- Research which is freely available for redistribution

Submit your manuscript at www.biomedcentral.com/submit
Ciomed Central 